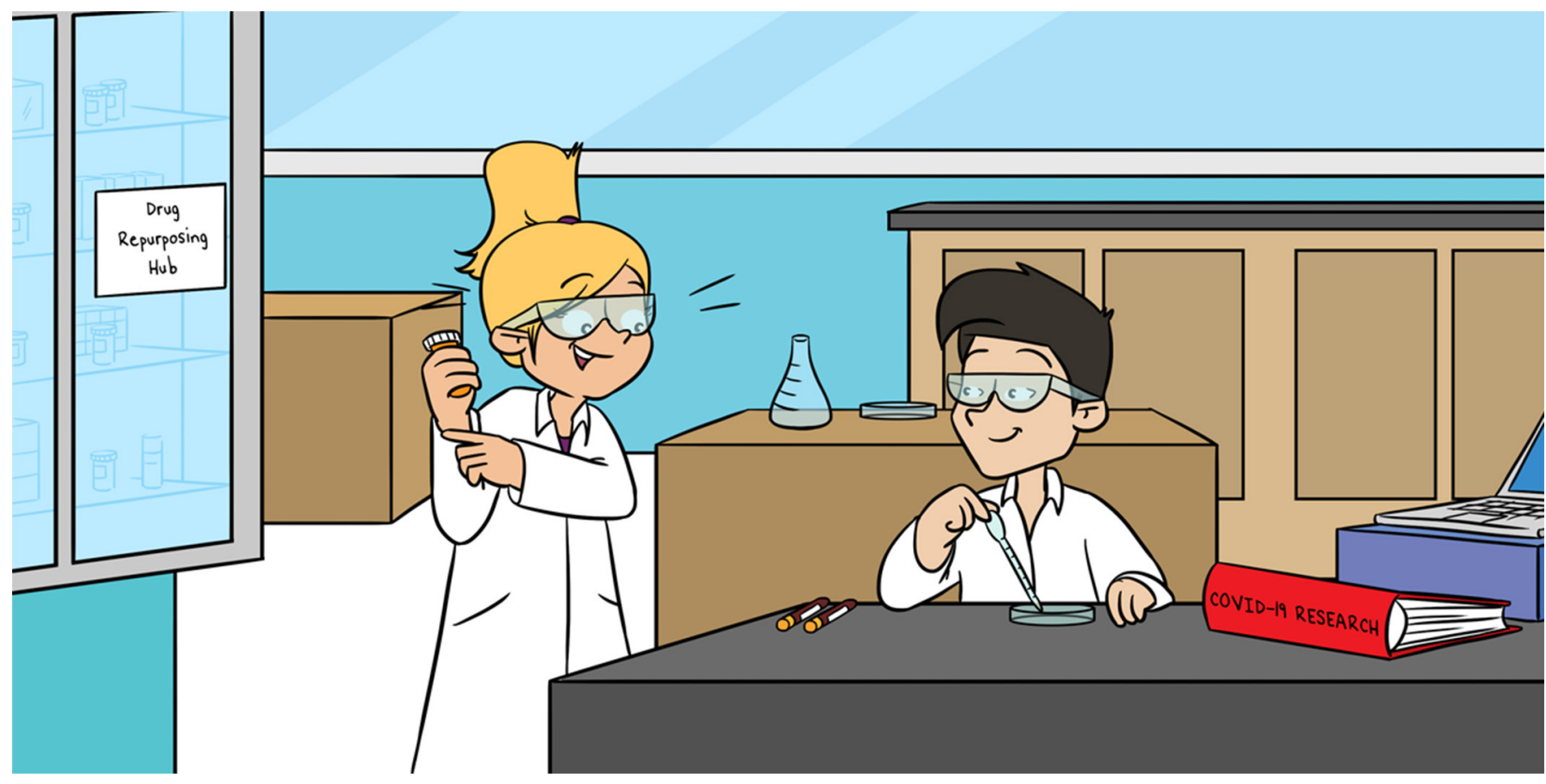

\title{
DRUG REPURPOSING: A QUICK AND EASY WAY OF FINDING NEW MEDICINES
}

\author{
Álvaro Mourenza ${ }^{1+}$, Natalia Bravo-Santano ${ }^{2+}$, José A. Gil ${ }^{1}$, Luís M. Mateos ${ }^{1}$ and Michal Letek ${ }^{1 *}$ \\ ${ }^{1}$ Área de Microbiología, Departmento de Biología Molecular, Universidad de León, León, Spain \\ ${ }^{2}$ ANGLE PLC, Guildford, United Kingdom
}

YOUNG REVIEWER:

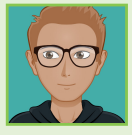

KIERAN

AGE: 13
Every year, we face infectious outbreaks produced by harmful microorganisms commonly called superbugs. Often, there is not enough time to find new treatments to cure infected patients. On average, it takes a decade to develop a promising new drug to the point where it can be used on patients! Also, many of the compounds that we identify in the laboratory as promising anti-infectives are not useful for treating patients, mainly because they have unexpected, unsafe side effects. However, researchers have already found thousands of drugs that can safely be used to treat specific diseases. These compounds are approved to be used on patients for particular illnesses, but many of them have not been tested to treat any other diseases. Some of these drugs could be repurposed to treat infections caused by new superbugs. In this article, we summarize some exciting strategies used to find new anti-infectives by drug repurposing. 
Figure 1

Drug repurposing can be achieved by literature search, screening collections of drugs in the laboratory, or by using computers and artificial intelligence (AI). Drug repurposing can identify new treatments for diseases that are very common, as well as rare or neglected diseases for which there is not enough funding to develop new drugs.

\section{ANTIBIOTIC}

A chemical produced by a microorganism that may kill bacteria or slow down their growth.

\section{SUPERBUG}

A microorganism that is difficult to treat or has become resistant to the drugs that are used to treat the infections it causes.

\section{DRUG}

REPURPOSING

Is the use of known drugs for new medical applications, which shortens the time and costs required to test their safety.

\section{ANTI-INFECTIVE}

A drug that could be used to cure people infected with a microorganism.
Literature review

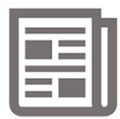

Screening drug libraries

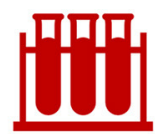

Computer analysis \& Al

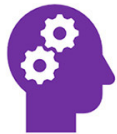

common disease

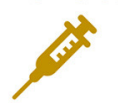

New treatment for a rare disease

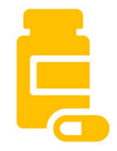

New treatment for a

New treatment for a

neglected disease

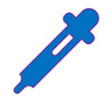

\section{INTRODUCTION}

Antibiotics were discovered in 1928 by Alexander Fleming [1]. Before antibiotics, bacterial infections were one of the leading causes of death worldwide and human life expectancy was only about 47 years. Since then, we have almost doubled that age in many countries. However, bacteria become resistant to antibiotics very quickly. New, harmful bacteria are still causing many deaths, because it takes time to find an effective cure or a new vaccine. These bacteria, as well as other dangerous microorganisms like viruses that appear rather suddenly and are difficult to treat, are often called superbugs.

The drug-development process is very costly and time consuming. The discovery of a new drug usually happens in the laboratory, and it may take years. New drugs are tested on animals to determine their safety, which is called preclinical research. This usually takes several months. If everything goes well in the preclinical phase, the drug is then tested on a small group of people to make sure that it is safe in humans, and then on larger groups of people until its safety and effectiveness are verified. Human testing might take several years [2].

However, instead of starting from scratch to develop a new drug each time a new superbug comes along, we could look at the thousands of safe drugs that have already been developed to treat other diseases, to see if they are effective against the new superbug. This is called drug repurposing (Figure 1), and it can allow us to uncover hidden talents of existing drugs. In this article, we will look at different examples of drug repurposing, a quick and easy way of finding new anti-infectives. 
PANDEMIC

A global

disease outbreak.

1 https://clue. io/repurposing\# conduct-screen

\section{AN INVISIBLE ENEMY ON OUR DOORSTEPS...}

We have all suddenly realized how damaging and disruptive a pandemic can be. The new virus that we are all fighting by staying at home with our families is making us very aware of how exposed we are to infections. Scientists and medical doctors all around the world have started a race against the clock to find new ways of protecting and treating people who are at high risk of developing a dangerous disease caused by the virus called SARS-CoV-2. This is a new strain of coronavirus that apparently jumped from animals to humans in late November 2019, in China. Since then, the whole world has stopped in its tracks to make sure that our hospitals do not become overwhelmed with people infected by the virus. If hospitals are overwhelmed, patients with severe complications of COVID-19 may not receive the proper treatment.

So far, there is no vaccine or known medication that can cure people with severe COVID-19. In many countries people is being vaccinated against SARS-CoV-2 but it will take quite a lot of time to produce it in sufficient amounts to protect everyone. As we mentioned earlier, it takes a long time-an average of 10 years - to develop a new drug that could be used in the clinic to treat people who are already sick with COVID-19. Many compounds that are identified in the laboratory as promising drug candidates do not pass all the trials, because they are not safe enough. We clearly need a Plan B to save infected people who are at risk of having a severe form of COVID-19. This group includes the elderly, people with liver or kidney disease, or people who have poor immunity, diabetes, obesity, chronic respiratory diseases, such as asthma, or serious heart conditions.

\section{DRUG REPURPOSING TO THE RESCUE!}

Luckily, over the years, researchers have already developed hundreds of new drugs against many different diseases. Many of these drugs have passed all testing and are now being used in the clinic to treat infections, strokes, or cancer. We know almost everything about those drugs, including the way they should be administered to patients, their maximum doses, and their side effects. Could we repurpose these well-known drugs to treat other diseases? The answer is yes! Often, drugs are developed for a specific purpose, such as treating one particular disease or condition. Scientists do not have time to check whether the drugs they are developing may be useful for treating other conditions as well. Fortunately, the many safe drugs that have already been developed are classified and distributed by the Broad Institute (Cambridge, Massachusetts) through an initiative called the Drug Repurposing Hub ${ }^{1}$. The collection currently includes over 6,500 compounds and it is growing every day. Anyone anywhere in the world can buy "libraries" of these drugs, consisting of small samples of each compound in laboratory tubes. 


\section{TUBERCULOSIS}

A respiratory disease caused by a bacterium called Mycobacterium tuberculosis.

STAPHYLOCOCCUS AUREUS

An important human pathogen that may cause skin, lung or blood infections, and it is becoming resistant to antibiotics.
The Drug Repurposing Hub is only one of many similar initiatives! All of this is making the work of finding a compound that could be repurposed to treat a new superbug much easier. We can do now massive screenings thanks to these collections of drugs, and we have already found several compounds that could be repurposed to treat COVID-19 [3]. We may be able to repurpose drugs that were used to treat malaria or infections caused by other viruses, such as HIV or Ebola. These drugs are being tested in extremely ill COVID-19 patients and we will know soon if they are truly effective.

Drug repurposing is not a new strategy-we have already repurposed drugs to fight against other superbugs. For instance, the bacteria causing the disease called tuberculosis are becoming resistant to most antibiotics. We urgently need treatments against this superbug, which is causing hundreds of thousands of deaths worldwide every year. Many drugs that were not originally developed as anti-infectives may be effective against tuberculosis, including drugs used to lower cholesterol levels or to treat diabetes [4].

Computers can help us with drug repurposing. A group of scientists from the Massachusetts Institute of Technology have recently used artificial intelligence to find new antibiotics from the Drug Repurposing Hub. They found a new drug that could be repurposed as an antibiotic to kill many different superbugs that are becoming resistant to antimicrobials [5]. A computer can process a lot of data without any of the scientists' preconceptions that may limit their search. Instead, the computer teaches itself how to find new drugs. This is speeding up the discovery of new anti-infectives. Most of the drugs have never been tested against infections because scientists did not think they could be useful as antimicrobials. In addition, the software used in this research work has been made freely available!

\section{OUR GROUP'S RESEARCH ON DRUG REPURPOSING}

Our research group also looked at repurposing drugs to treat infections caused by an extremely dangerous superbug, Staphylococcus aureus [4]. These bacteria are quickly becoming resistant to all available antibiotics. Antibiotic-resistant strains are being isolated from patients even when a new antibiotic has only been used in the clinic for 1 year. The rate at which we are discovering new antibiotics is not fast enough to deal with this crisis. Moreover, many big pharmaceutical companies have lost interest in working to find new antibiotics. After all, they may lose all the money and time invested as soon as a superbug becomes resistant to a newly discovered drug. In the case of $S$. aureus, the situation is even more complicated, as this bacterium can hide and replicate inside of human cells. Unfortunately, many antibiotics do not get into infected human cells because they cannot get through the cell membrane. So, S. aureus bacteria may survive inside the cells of infected people, even if the bacteria are susceptible to the antibiotics used to treat the patients. 


\section{OXIDATIVE STRESS}

A process that can use oxygen to damage proteins, DNA, or lipids in bacteria. This process can kill bacteria.

In our laboratory, we searched for drugs that could be repurposed to fight $S$. aureus. We found hundreds of very promising drugs that could be combined with traditional antibiotics to treat human cells infected by S. aureus [4]. Many of these drugs have been identified to treat other diseases, but they have never been used to cure infected people.

In addition, we recently found that some antibiotics have a hidden superpower-they may produce a condition called oxidative stress, which may kill bacteria [6]. Oxidative stress is a process that can use oxygen to damage proteins, DNA, or lipids in bacteria. Most of the antibiotics that induce oxidative stress are not very effective against superbugs if they are used individually, but they are very effective when we combine them. In the lab, we produced mutant superbugs that were extremely susceptible to oxidative stress. We used these mutants to look for antibiotics that have this new powerful effect on bacteria. By doing so, we found some antibiotics that are normally used to treat urinary tract infections, which could be repurposed to treat respiratory infections [6].

\section{CONCLUSION}

We are living in a world that is changing very quickly. Old and new superbugs can completely stop our lives in a matter of days. We need new strategies to combat the viruses and bacteria that are causing infections for which we do not yet have a treatment. Vaccines are often extremely difficult to develop because many pathogens are very good at hiding from the immune system, which is why many vaccines fail. In addition, many bacteria are becoming resistant to antibiotics. This is threatening one of the pillars of modern medicine [1]. Without antibiotics, all progress made on organ transplants or cancer treatment is in danger. Even a small wound could suddenly become dangerous if antibiotics are not effective. Wounded people could develop bacterial infections that could make their lives much shorter. Without antibiotics, we could be back at the beginning of the last century and live a maximum of 47 years in many countries. Today, that short life expectancy is doubled, due in great part to the drugs available to treat infections. We need to increase the list of drugs that could be used as anti-infectives, and drug repurposing can be a cheap and easy way to recycle many of the thousands of medications that have already been discovered and safety tested!

\section{ACKNOWLEDGMENTS}

We want to thank the Junta de Castilla y León (Spain) for funding our research work on drug repurposing (Ref. LE044P20).

\section{REFERENCES}

1. Letek, M. 2020. Alexander Fleming, the discoverer of the antibiotic effects of penicillin. Front. Young Minds 8:159. doi: 10.3389/frym.2019.00159 
2. U.S. Food \& Drug Administration. The Drug Development Process. Available online at: https://www.fda.gov/patients/learn-about-drug-and-deviceapprovals/drug-development-process (accessed January 04, 2020).

3. Schlagenhauf, P., Grobusch, M. P., Maier, J. D., and Gautret, P. 2020. Repurposing antimalarials and other drugs for COVID-19. Travel Med. Infect. Dis. 2:101658. doi: 10.1016/j.tmaid.2020.101658

4. Bravo-Santano, N., Behrends, V., and Letek, M. 2019. Host-targeted therapeutics against multidrug resistant intracellular Staphylococcus aureus. Antibiotics (Basel). 8:241. doi: 10.3390/antibiotics8040241

5. Stokes, J. M., Yang, K., Swanson, K., Jin, W., Cubillos-Ruiz, A., Donghia, N. M., et al. 2020. A deep learning approach to antibiotic discovery. Cell 180:688-702.e13. doi: 10.1016/j.cell.2020.01.021

6. Mourenza, Á., Gil, J. A., Mateos, L. M., and Letek, M. 2020. A novel screening strategy reveals ROS-generating antimicrobials that act synergistically against the intracellular veterinary pathogen Rhodococcus equi. Antioxidants (Basel) 9:114. doi: 10.3390/antiox9020114

SUBMITTED: 18 April 2020; ACCEPTED: 11 December 2020; PUBLISHED ONLINE: 25 January 2021.

EDITED BY: Michel Goldman, Institute for Interdisciplinary Innovation in healthcare (I3h), Belgium

CITATION: Mourenza Á, Bravo-Santano N, Gil JA, Mateos LM and Letek M (2021) Drug Repurposing: A Quick and Easy Way of Finding New Medicines. Front. Young Minds 8:553424. doi: 10.3389/frym.2020.553424

CONFLICT OF INTEREST: The authors declare that the research was conducted in the absence of any commercial or financial relationships that could be construed as a potential conflict of interest.

COPYRIGHT @ 2021 Mourenza, Bravo-Santano, Gil, Mateos and Letek. This is an open-access article distributed under the terms of the Creative Commons Attribution License (CC BY). The use, distribution or reproduction in other forums is permitted, provided the original author(s) and the copyright owner(s) are credited and that the original publication in this journal is cited, in accordance with accepted academic practice. No use, distribution or reproduction is permitted which does not comply with these terms.

\section{YOUNG REVIEWER}

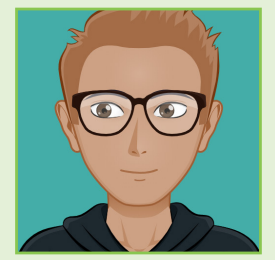

\section{KIERAN, AGE: 13}

My name is Kieran, I am 13 years old and I am in third grade of secondary school. I love playing basketball and eating pizza. My parents are doctors, so they talk a lot about science to me and my older brother-an important thing I have learned is to always check what the source is for any piece of information I come across. 

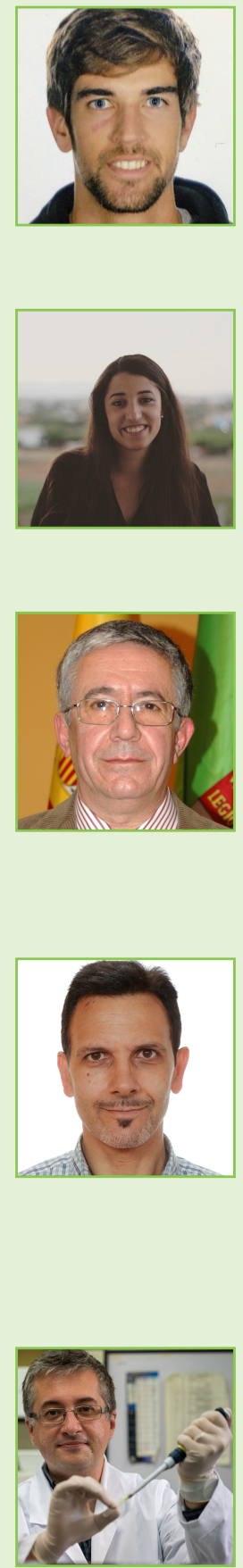

\section{AUTHORS}

\section{ÁLVARO MOURENZA}

I have focused on the molecular biology of microorganisms. I studied biofuels' production by microorganisms, and now I am focused on the mechanisms used by pathogens to overcome the defenses of their hosts, which allows their survival and growth during infection. I am also interested in antibiotic resistance and how science can fight against antimicrobial-resistant bacteria.

\section{NATALIA BRAVO-SANTANO}

I am interested in finding cures for human diseases. Working at the university, I studied how bacteria survive inside host cells, and I tried to identify new treatments against these bacterial infections. Now, working in a biopharmaceutical company, I develop tools to detect cancer cells in our bodies and improve cancer diagnosis.

\section{JOSÉ A. GIL}

Once upon a time (during the last century), I worked with Streptomyces, a type of bacteria that produces a vast amount of different antibiotics, and we developed genetic engineering strategies to clone genes involved in antibiotic production. During the last 20 years, we have studied how industrially-important bacteria, such as Corynebacterium, grow and divide and how they cope with toxic compounds, such as arsenic.

\section{LUÍS M. MATEOS}

My research interests have always been focused on studying a broad group of bacteria belonging to the corynebacteria cluster: mostly Corynebacterium, Rhodococcus, and Mycobacterium. My initial research was focused on bacterial primary metabolite production, including amino acids and nucleotides. However, more recently, we looked at bioremediation opportunities by using bacteria as containers for heavy metals accumulation, and we also studied the oxidative stress generated when toxics agents are inside the bacterial cells.

\section{MICHAL LETEK}

My research work has always been focused on identifying new ways to control bacterial pathogens. Over the last few years, I have studied how bacteria grow and divide, how they interact with their host during infection, and the host response to bacterial infection. I aim to find novel therapies to control bacterial pathogens and to understand what makes us susceptible to infections caused by microorganisms, such as Staphylococcus aureus or Mycobacterium tuberculosis. * michal.letek@unileon.es

${ }^{\dagger}$ These authors have contributed equally to this work 